DOI https://doi.org/10.18551/rjoas.2020-09.08

\title{
THE SATISFACTION INDEX OF TOURISTS EXPERIENCE QUALITY: A CASE STUDY IN BALI TOURISM DESTINATION
}

\author{
Arismayanti Ni Ketut*, Budiarsa Made, Bakta I Made, Pitana I Gde \\ Faculty of Tourism, Udayana University, Bali, Indonesia \\ ${ }^{\star}$ E-mail: arismayanti pariwisata@unud.ac.id
}

\begin{abstract}
Tourism is very dependent on the quality of the tourist experience, understanding the factors that encourage them to visit destinations and their needs in traveling is an important thing for destination management because it affects satisfaction which has implications for tourist loyalty. This research aims to analyze the satisfaction index of tourism experience quality. The technique of collecting data was done by partipatory observation, questionnaire and interview. This study uses 14 indicators to measure the quality of the tourist experience. The data analysis technique was applying Customer Satisfaction Index. This research was conducted in Bali by involving 600 tourists as sample in 6 tourist attraction. The the index of experience quality satisfaction showed very satisfying value. The quality of the tourist experience on tourist attractions and tourism destinations needs to be continuously improved, especially in indicators of hedonism, novelty, meaning, recognition and perceived quality of the destination.
\end{abstract}

\section{KEY WORDS}

Satisfaction, tourist experience, quality, Bali.

Tourism is highly depends on the quality of tourists' experience and consequences of assesment toward the satisfaction or their dissatifacion (Ladhari, 2009; Saha dan Theingi, 2009). For that reason, it is important for tourism businesses to understand the importance of tourists' perception about their experiences, working hard to measure, and keep finding way to improve tourists' satisfaction. An impressive tourism experience will lead to service quality perception, tourists' satisfaction, and the intention of post consumption behavior (Filieri et al., 2017). Satisfied tourists tend to communicate their positive experience to others and also tend to have revisit/repeat purchase (Kozak dan Rimmington, 2000). Understanding the need of the tourists is important thing done by the management of tourism destination ( $\mathrm{Yu}$ and Weiler, 2001). The tourists' satisfaction influence the tourists' loyality toward destination, recommendation of word of mouth and the intention to revisit (Chen dan Tsai, 2007; Chi dan Qu, 2007; Yuksel et al., 2010; Kim dan Brown, 2012; Rajaratnam et al., 2015; Dalimunthe et al., 2019).

When tourists have more experiences and sophisticated, they will not longer willing to compromize with standard services (Kandampully, 1997: 4). Tourists are more aware for their rights as customers and as a result, become more self confidence in demanding compensation for bad quality. In a more competitive environment, tourism business 'fight to move forward toward the new model based on the competitive excellence, based on quality' (Harrington and Lenehan, 1998). Therefore, investing in quality can cause a significant long term cost savings (Pender and Sharpley, 2005). The experience quality becomes very important which will establish the satisfaction or loyalty of tourists in visiting a tourism destination. The whole image of a destination not only effects the process of the choosing of destination, but also the intentation of behavior of tourists in general (Qu et al., 2011). The tourism destination quality is significant in influencing the tourists' satisfaction which in turn influence behavior intenation significantly (Rajaratnam et al., 2015; Wang et al., 2017). The tourism destination is developed for sustanaible goals, they are having the capability to be competitive, overcome challenges, able to attract tourists for the first time and improve their loyalty, stay unique culturally and stay balance with the environment. Therefore, tourism is said to be sustainable, to be able to balance two types of needs satisfaction, they are: the 
economy development and the protection of natural protection as a whole. The sustainable tourism strategy involved three aspects, they are 1) qualified tourism, being sustanaible in giving valuable experience for visitors, and also improving the society's life quality-becomes host and protect the enviroment, 2) Sustainable, sustainable tourism ensures the nature sustainability based on the culture of the society-host, a satisfying experience for visitors; and 3) Equilibrium, it is a sustainable tourism which ensure the balance need of tourism industry, environment lovers and local society (Gherco and Trandafir, 2014).

On the other hand, a visiting tourist is expected to gain experiences according to their expectation. A good experience will leave good memory and create positive image toward a tourism destination. Tourists in the coming future, not only will revisit to that tourism destination, but also will give recommendation to tourists or potential will-be tourists, directly or through review on media (such as social media, tripadvisor, traveloka). To establish tourists' loyalty is not a choice in business, but the only way to develop a sustainable competitive excellence. The effort to establish qualified tourism through the development of tourism destination quality and the quality of tourists' experience should be needed to be done continuously. The ideal, a developing tourism on a region is expected to give economic benefit and welfare to society. Thus the society has high awareness to also keep and develop tourism. Also, the quality of experience of a visiting tourist is essential in tourism business. Each tourism product which enjoyed by tourist will create unforgettable tourism experience. Sometimes tourism experience is not only delight, considering tourism is not only provided by one industry or service providers, but various industries or service providers can be found in a tourism destination. A delightful experience will create satisfaction tourists so it will increase the tourists' loyalty. The bad experience has risk on the negative image which created toward the tourism destination. The objective of the research to analyze the index of satisfaction of tourists' experience quality on a tourism destination.

\section{LITERATURE REVIEW}

The previous research applied the quality variable of tourists' experience which reffered in this research by Kim et al., (2012); Radder and Han (2013); Sukanthasirikul and Trongpanich (2015); Schlesinger et al. (2015); Smith et al. (2016); Frenandes and Cruz (2016); Aliman et al. (2016); Ismail et al. (2016); Dioko and So (2017); Soteriades (2017); Blazeska et al. (2018); and Dalimunthe et al. (2019). The current research has similar equation about the quality experience variable on tourism destination by combining indicator from previous research (Kim et al., 2012; Schlesinger et al. 2015; Frenandes dan Cruz, 2016; Ismail et al., 2016; Soteriades, 2017; Blazeska et al., 2018), therefore resulting in 14 indicators and 66 attributes on the tourists' experience quality variable. The indicators were developed and adjusted with characteristic and adjustment of tourism destination which was conducted by the researched in Bali. Other equation on data collection with survey technique by questionnaire distribution to visitors/tourists. Different from the previous research which was applied approach/technique of qualitative data analysis, such as Smith et al. (2016) by interpretive constructivis approach by applying fenomenology and ethnography; Dioko dan So (2017) was analyzed by time-span of separate cross-sectional; and Dalimunthe et al. (2019) conducted literature review about experience quality. The quantitative research conducted by Sukanthasirikul and Trongpanich (2015) which applied modelling technique of Structural Equation Model (SEM); Walesska et al. (2015) applied Analysis of Variance (ANOVA) and Kruskal-Wallis non-parametric Kruskal-Wallis tested; Aliman et al. (2016) applied descriptive statistic, factor analysis and multiple regression;; Ismail et al. (2016) quantitative approach through Exploratory Factor Analysis (EFA); and Soteriades (2017) quantitative approach and convenience sampling technique. The research which conducted at present applying Customer Satisfaction Index (CSI).

Concept of Tourist Experiences. The tourist experience is an interaction between tourists and a tourist destination, where the tourist destination becomes a site of experience and tourists become the actor of that experience (Stamboulis and Skayannis, 2003). Larsen (2007) argues that tourist experiences should be defined as events related to past travel that 
are significant enough to be stored in long-term memory. Selstad (2007) defines tourist experience as a combination of novelty in the search for individual identity and selfrealization. The factors that influence the tourist experience, namely: visitors, products (or tourism destinations), and local communities. Visitors arrive at a tourism destination with perceptions about the type of experience that is influenced by the individual's social construction and perceptions originating from the media, product information and descriptions, prior knowledge, expectations, and previous travel experiences. Tourism products generally refer to experiences with the tourism industry, the public sector, and formal cultural intermediaries (such as travel agents or tour guides). The quality of products and services during a trip is considered to be an important component. The availability of services and activities can influence an individual's need or desire for certain experiences. If tourists are motivated by adventure, they will look for destinations that offer active recreational activities. Likewise, vice versa, therefore, the types and quality of products and services available in a destination can greatly affect the experience of tourists while traveling in that tourism destination (Ryan, 2002). Anderreck et al. (2006) argued that social interactions affect the perceived quality of experience. Therefore, the physical and social aspects of a destination influence the experience and evaluation of the entire trip. If the expectations of the experience are met or exceeded, then satisfaction will result. Dissatisfaction occurs when the experience doesn't live up to expectations.

Customer Satisfaction Theory. Customer satisfaction theory is used to assess the quality level of the tourist experience. The quality of the tourist experience is closely related to tourist satisfaction when visiting a tourism destination. Product quality (goods and services) and customer satisfaction, it has been reached a consensus that customer expectations play an important role as a standard of comparison in evaluating quality and satisfaction. According to Olson and Dover (in Tjiptono and Chandra, 2011) customer expectations or expectations are customer beliefs before trying or buying a product, which is used as a standard or reference in assessing the performance of the product concerned. However, the conceptualization and operationalization of customer expectations is still a controversial issue, especially regarding the characteristics of specific expectations standards, the number of standards used, and the source of expectations. Every consumer may have different pre-consumption expectations. In addition, different consumers may apply different types of expectations to different situations.

In a literature review of customer satisfaction conducted by Giese and Cote (2002), identified twenty definitions referred to in customer satisfaction research over a period of thirty years. Although the definitions vary (some of which are inconsistent with each other), the two experts from Washington State University found similarities in terms of three main components, namely: 1) Customer satisfaction is a response (emotional or cognitive); 2) The response involves a specific focus (expectations, products, consumption experiences, and so on); and 3) The response occurs at a certain time (after consumption, after the selection of products / services, based on accumulative experience, etc.). Expectations of product performance serve as a standard of comparison to the actual performance of the product. Some experts identify the concept of expectation before purchase (Wilton, 1988; Spreng, 1996 in Hasan, 2008: 62), namely: 1) Equitable performance is a normative assessment of the performance that customers should receive in proportion to the costs and efforts that have been put into buying and consuming products ; 2) Ideal performance is the optimum level of performance expected by a customer; and 3) Expected performance is the level of performance that is predicted or the most expected-liked by consumers. Customer expectations will continue to grow in accordance with environmental changes that provide information and increased customer experience which will affect the level of satisfaction felt by customers.

Customer expectations have a big role in determining product quality and customer satisfaction. Basically, a close relationship between quality determination and customer satisfaction. In evaluating it, customers will use their expectations as a reference standard. Customer expectations are the reason why the same two business organizations can be judged differently by their customers. The factors that determine customer expectations, 
namely (Zeithaml, et al., 1993): 1) Enduring service intensive is a factor that is stable and encourages customers to increase their sensitivity to service products; 2) Transitory service intensive is a temporary individual factor that increases the sensitivity of customers to services, due to an emergency situation when the service is needed or the last service consumed; 3)Personal needs are physical, social, and psychological needs that a person feels will be the basis for their welfare which determines their expectations; 4) Perceived service alternatives are customer perceptions of the service level of other similar companies; 5) Self-perceived service roles are customers' perceptions of their level of involvement in influencing the services they receive, consumers are involved in the service provision process; 6 ) Situational factors are all possibilities that can affect service performance that are beyond the control of the service providers; and 7) Positive word of mouth is a positive recommendation from other trusted people (experts, friends, family, and media publications) that are more quickly accepted as a reference, because service customers have difficulty evaluating services that they have not experienced themselves.

According to Schnaars (1991: 298), basically the goal of a business is to create satisfied customers. In line with this, various attempts have been made to develop a theoretical framework to explain the determinants, formation processes and consequences of customer satisfaction. Broadly speaking, customer satisfaction research is based on three main theories, namely: First, Contrast theory assumes that consumers will compare actual product performance with pre-purchase expectations. If the actual performance is greater than or equal to expectations, the customer will be satisfied. Conversely, if the actual performance is lower than expectations, the customer will not be satisfied. Second, Assimilation theory states that after-purchase evaluation is a positive function of prepurchase consumer expectations. If the psychological disconfirmation process is not comfortable to do, then the customer tends to perceptually distort the difference between expectations and performance towards the initial expectations. In other words, deviations from their expectations are likely to be accepted by the customer. Third, Assimilation-contrast theory assumes that the occurrence of the assimilation effect or contrast effect is a function of the level of disparity between expected and actual performance. If the gap is large, consumers will enlarge the gap, so that the product is perceived to be much better / worse than the reality. However, if the gap is not too big, the assimilation theory applies. In other words, if the acceptable range of deviation is passed, the gap between expectations and performance will be significant and that's when the contrast effect takes effect. The modern tourism perspective, apart from the consumer elements that determine behavior, an increasing role is played by the results, the experiences gained at the sites visited, these experiences are valued at a level (Bowen and Clarke, 2009): personal satisfaction, the extent to which tourists' expectations fulfilled; the needs of the host community are understood in the complexities of that society, namely economic growth and prosperity, the preservation of customs and traditions; and environmental quality.

\section{METHODS OF RESEARCH}

This research was conducted in Bali, especially in 6 tourist attractions in Bali, namely: Tirta Empul, Penglipuran Village, Tanah Lot, Monkey Forest, Lovina, and Banjar Hot Springs. The tourist attractions selected are based on variations in the dominant tourism potential that they have (cultural, natural, artificial), trends in the number of tourist visits (increasing, decreasing, and fluctuating), the characteristics of tourists visiting by nationality, as well as variations in locations based on districts in Bali. Based on these considerations, it is hoped that the chosen tourist attraction will be representative of the conditions of Bali's tourism destinations. Bali is a province in Indonesia which is known as the Island of the Gods. The total area of Bali Province reaches $5.780,06 \mathrm{~km} 2$ or 0.30 percent of the Indonesian archipelago. Bali is one of the provinces in Indonesia with a population of around 4.246.500 people. This tourist destination is visited by more than 15 million tourists (15.828.464 people in 2018) who are dominated by domestic tourists (61.65 percent). Tourist visits within 12 years increased by an average of 10 percent (2006-2018 average increase of 10.74 percent) 
to Bali. Bali with an area of $5.636,66 \mathrm{~km}^{2}$ or 0.29 percent of the total area of Indonesia, however is able to attract more than 40 percent of total tourist visits to Indonesia (BPS Provinsi Bali, 2018).

This study used a survey research design, in which researchers asked respondents' perceptions regarding the quality of tourist experience, both the level of performance / satisfaction and the level of importance. The questionnaire model and construct greatly determine the success of the survey conducted. The tourist experience is an interaction between tourists and a tourist destination, where the tourist destination becomes a site of experience and tourists become the actor of that experience (Stamboulis and Skayannis, 2003). The variable quality of the tourist experience consists of 14 indicators, namely: hedonism; novelty; local culture; refresh; meaningfulness; involvement; knowledge; peace of mind; recognition; environment; service providers; satisfaction; giving recommendations; and the quality of the destination felt (Kim et al., 2012; Schlesinger et al. 2015; Frenandes and Cruz, 2016; Ismail et al., 2016; Soteriades, 2017; Blazeska et al., 2018) then developed into 66 attributes.

The population in this study were all tourists visiting Bali. Based on the calculation of the Slovin formula, a sample size of 100 people can be obtained for each tourist attraction, bringing the total to 600 tourists. To measure the quality of tourism destinations and the quality of experience visiting Bali, 600 tourists in Bali are used, which is a combination of the number of samples at each tourist attraction with a Bali sampling error rate of 4 percent taken accidentally in the field. The types of data used in this research are qualitative and quantitative data. Sources of data used in this study, namely primary and secondary sources. The data collection techniques used in this study were: participatory observation, questionnaires, and interviews. The research scale used in this study is a Likert scale which consists of five intervals (1-5) which use a positive response to a negative response. Respondents can choose one of the five internal. The validity of data in qualitative research is a very important part of knowing the degree of trustworthiness of the results of research that has been carried out using triangulation techniques in data collection, so the data obtained will be more consistent, so that it becomes valid and accountable data. Researchers used participatory observation, questionnaires, interviews, and documentation for the same data source simultaneously. The data analysis techniques used in this study was CSI.

\section{RESULTS AND DISCUSSION}

Tourist Characteristics. The characteristics of tourists visiting Bali are dominated by male tourists, but not significant (56.67 percent); young adults (25-44 years reaching 63.50 percent); undergraduate education level (61.83 percent); and work (86.50 percent). The dominant tourists came from Asia (49.67 percent). Tourists who visited for the first time dominated (63.17 percent), and were dominant in obtaining information from the internet (39.00 percent). The length of stay of tourists is dominated by 4-7 days (42.83 percent). When traveling, tourists dominate using charter modes of transportation (60.50 percent) in the form of rental cars, travel agent cars, or buses. This is expressed by tourists when traveling with this mode of transportation, tourists feel comfortable, practical, and flexible as well as the convenience if they want to visit the next place or tourist attraction in Bali. Meanwhile, the type of accommodation chosen by tourists while traveling in Bali is predominantly commercially managed accommodation ( 94.50 percent) in the form of hotels, villas, homestays, cottages and guest houses.

Tourist Experience Quality Satisfaction Index. The quality of the tourist experience on a tourist attraction is measured using 14 indicators and 66 attributes. The indicators are: hedonism; novelty; local culture; refresh; meaningfulness; involvement; knowledge; peace of mind; recognition; environment; service providers; satisfaction; giving recommendations; and the quality of the destination felt. Calculating the level of importance of the quality of the tourist experience by determining the Mean Importance Score (MIS) for each attribute. Based on each Likert scale score, the level of importance and satisfaction of the tourist 
experience can be seen from the gap between the value of satisfaction and the interests of tourists' expectations. The gap that shows a positive value shows that these indicators and attributes have met the expectations of tourists. Meanwhile, the negative value indicates that the attribute indicators have not met the expectations of tourists, so that improvement efforts are needed in each indicator. The smaller the gap between performance and interests / expectations means the better the level of tourist satisfaction, and vice versa. The comparison of satisfaction and the importance scores of the quality of the tourist experience can be seen in Table 1.

Table 1 - The Comparison of Satisfaction and the Importance scores of the Quality of Tourist Experience in Bali

\begin{tabular}{|c|c|c|c|c|}
\hline No. & Indicators & Satisfaction scores & Importance scores & Gap \\
\hline 1. & Hedonisme & 4.13 & 4.19 & -0.06 \\
\hline 2. & Novelty & 4.03 & 4.10 & -0.07 \\
\hline 3. & Local culture & 4.31 & 4.32 & -0.01 \\
\hline 4. & Refresh & 4.24 & 4.30 & -0.06 \\
\hline 5. & Meaningfullness & 4.14 & 4.17 & -0.03 \\
\hline 6. & Involvement & 4.19 & 4.26 & -0.07 \\
\hline 7. & Knowledge & 4.25 & 4.32 & -0.07 \\
\hline 8. & Peace of mind & 4.12 & 4.20 & -0.08 \\
\hline 9. & Recognition & 4.11 & 4.19 & -0.08 \\
\hline 10. & Environment & 4.30 & 4.37 & -0.07 \\
\hline 11. & Service providers & 4.20 & 4.28 & -0.08 \\
\hline 12. & Satisfaction & 4.34 & 4.38 & -0.04 \\
\hline 13. & Giving recomendation & 4.30 & 4.34 & -0.04 \\
\hline 14. & The quality of destination felt & 4.21 & 4.30 & -0.09 \\
\hline
\end{tabular}

Based on Table 1, it can be seen that most of the attributes on the satisfaction indicator show negative values. This means that almost all indicators and attributes have not met the expectations of tourists. However, there are several attributes that show positive values, including: giving pleasure; experience close to local culture; and consider other types of objectives regarding service quality. In the life view indicator, the quality of the tourist experience has an advantage in the attribute of giving pleasure. Weaknesses are in the attribute of doing something that is very popular, namely tourists assessing the lack of tourist activity on tourist attractions limits the space for tourists to create experiences that match their preferences, namely tourists assess existing tourist attractions giving a monotonous impression to the characteristics new tourists at this time. On the indicator of recency, the quality of the tourist experience has an advantage on the once-in-a-lifetime experience attribute and is unique. Weaknesses in different attributes from previous experiences, this can be seen from the lack of uniqueness as a differentiator of Bali tourism destinations (differentiation) from other destinations or tourist attractions with one another.

Viewed from the indicator of local culture, the quality of tourist experience has an advantage in the attributes of experience that are close to local culture. Weakness in the good impression attribute of local residents). On the refreshing indicator, the quality of the tourist experience has an advantage on the revitalized attribute. Weakness in the attribute of enjoying a sense of freedom. On the indicator of meaning, the quality of the tourist experience has an advantage in the attributes of doing something important. Meanwhile, the weakness in the attribute does something meaningful. Meanwhile, the weakness in the attribute does something meaningful. In the engagement indicator, the quality of the tourist experience has an advantage in the attributes involved in the travel process. Weakness in the attribute of feeling being educated and informed. Many tourists complain about the limited information about tourist attractions, tourist activities, cultural, philosophical, historical activities and meanings, signs that can be accessed by tourists. On the knowledge indicator, the quality of the tourist experience has an advantage over the new cultural attributes). While the weakness is in the exploration attribute.

On the indicator of peace of mind, the quality of the tourist experience has the advantage of feeling physically comfortable). While the weaknesses are in the attributes of feeling relaxed, feeling a sense of personal security, and feeling that privacy is guaranteed. 
On the recognition indicator, the quality of the tourist experience has an advantage in the cooperation attribute. Weaknesses in attributes are taken seriously, this is because tourists want to get attention, priority scale and something that is conveyed gets a good response. In environmental indicators, the quality of the tourist experience has an advantage on the social factor attributes. While the weakness is in the design attribute, this relates to the creation of space that enhances the natural, social, cultural and physical environments of tourist attractions. In the service providers indicator, the quality of the tourist experience has advantages in the communication and reliability attributes. While the weakness is in the competency attribute, this is related to the ability or capacity of service providers to perform various tasks in a job, where the ability is determined by intellectual and physical factors.

In the satisfaction indicator, the quality of the tourist experience has a weakness in the attribute considering other types of objectives related to service quality. This of course has implications that are not good for tourist attraction. Another weakness in the tourist attractiveness attribute really catches the customer's attention. In the indicator of giving recommendations, the quality of the tourist experience has an advantage in the attributes of recommending it to others and when asked will recommend a destination for vacation. While the weakness is in the attribute of encouraging people around tourists to come.

On the indicators of perceived destination quality, the quality of the tourist experience has an advantage in the attribute of providing tourist offers with consistent quality. Tourism as a service industry is greatly influenced by the quality of services provided by human resources service providers. Given that there are no standards for service delivery and management of tourism destinations or tourist attractions, inconsistencies in service delivery are likely to occur.

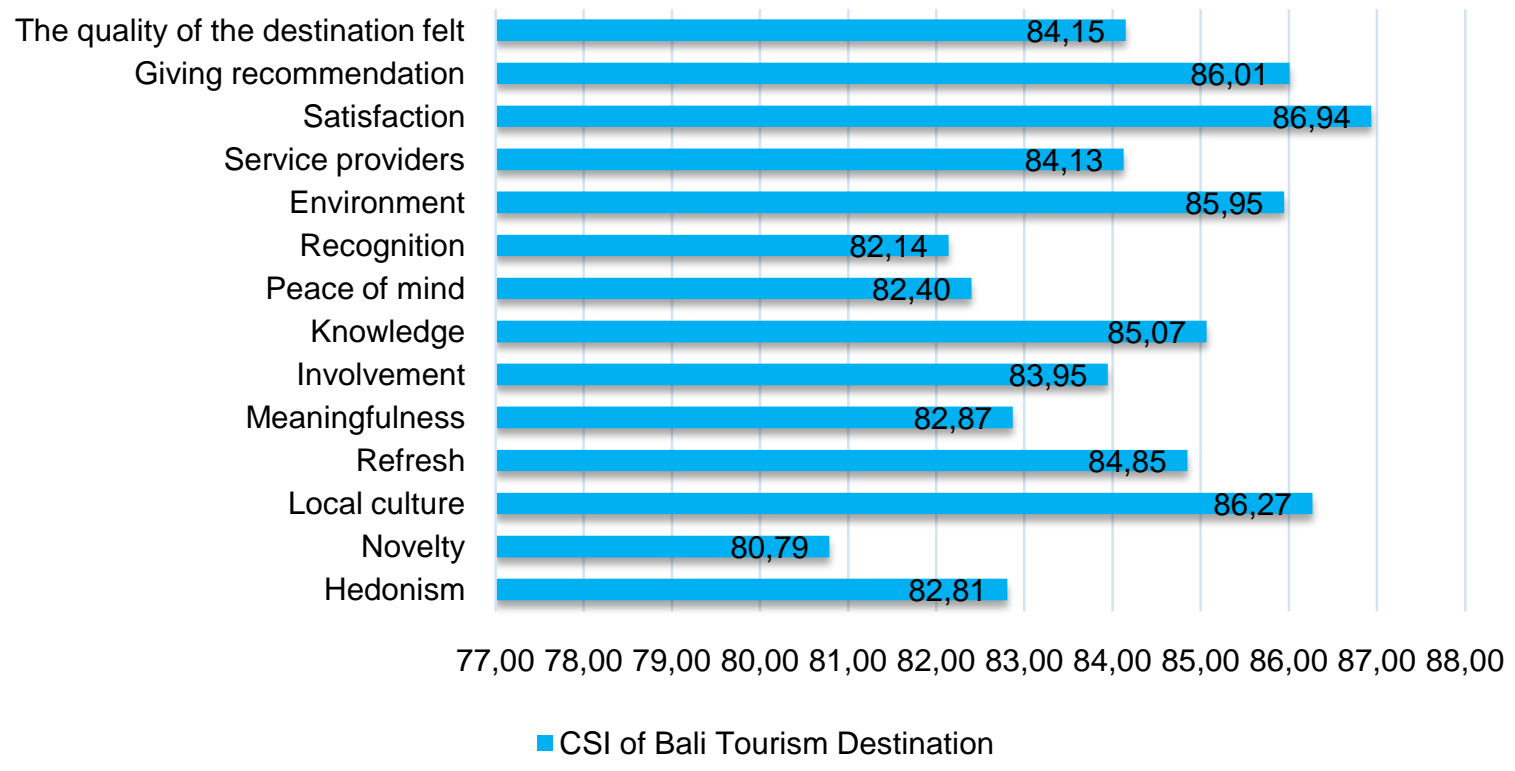

Figure 1 - Customer Satisfaction Index of the Toourist Experience Quality in Bali

In Figure 1, it can be seen that the very satisfied value on the quality of the tourist experience is shown in most of the indicators, including: satisfaction indicators (86.94), local culture (86.27), giving recommendations (86.01), environment (85.95), knowledge (85.07), refresh (84.85), destination quality (84.15), service providers (84.13), involvement (83.95), meaningfulness (82.87), hedonism ( 82,81$)$, peace of mind $(82.40)$, and confession $(82 ., 14)$. Meanwhile, the novelty indicator obtained a satisfied value (80.79). Based on the comparison of the level of quality of the tourist experience in Bali tourism destinations with tourist attractiveness referring to the calculation of the level of satisfaction and importance of the tourist experience it has an average of 84.17 (very satisfied). The quality of the tourist experience needs to be continuously improved, especially in indicators of hedonism, novelty, 
meaningfulness, recognition and the quality of the destination felt. Expectations of tourists will continue to develop in accordance with changes in the environment that provide information and increase tourist experiences which will affect the level of satisfaction felt by tourists. Tourists have a big role in determining product quality and customer satisfaction. Basically there is a close relationship between determining quality and tourist satisfaction. In evaluating it, tourists will use their expectations as a reference standard. The dominance of information sources through family / friend recommendations and the internet of tourists visiting Bali shows positive word of mouth, namely positive recommendations from trusted people (experts, friends, family, and media publications) are more quickly accepted as references, because tourists have difficulty evaluating tourism products or services that they have not experienced themselves, considering that the dominant tourists are first-time visitors. This opportunity is a very potential thing to do our best to create satisfied tourists

This study uses a contrast theory which assumes that tourists will compare actual product performance with pre-purchase expectations. If the actual performance is greater than or equal to expectations, the tourists will be satisfied. Conversely, if the actual performance is lower than expectations, tourists will not be satisfied. However, increasing tourist satisfaction must be followed by meeting the needs and increasing the welfare of the community as hosts with various roles played in social, cultural and economic life, as well as improving the quality of the environment for the sustainability of a superior tourism destination. Based on the results of the analysis and discussion, the findings in this study contributes to showing the most important indicators (satisfaction) in assessing the quality of tourist experience, indicators (satisfaction) which has the highest performance in assessing the quality of the experience. The findings of this study have the following implications: to understanding and knowledge of the characteristics of visiting tourists, knowing the needs and wants, likes and dislikes, as well as assessing the indicators and attributes that shape the creating quality experiences are important things for tourism destination management to do. The competitive advantage of tourism destinations can be achieved by packaging natural, cultural, atmosphere and environmental tourism products, as well as hospitality which is an advantage and differentiator from other tourism products of Bali tourism destinations. The advantages possessed by Bali's tourism destinations are valuable, rare, not easy to imitate. The indicators and attributes considered important by tourists must be continuously improved so that they can differentiate themselves from competitors through quality. Quality is an investment that leads to significant cost savings in the long run. This is confirmed by the findings of Yeoh and Roth (1999).

Sources of information obtained by tourists as a reference for visiting Bali tourism destinations are dominated by information on the internet and recommendations from family / friends. This has implications for the effectiveness of the promotional media that will be used by tourism destination management in promotion to make it more targeted, effective and efficient in the allocation of resources. In Bali tourism destinations there has been a shift towards the use of travel agent services, advertising and other print promotion media which are starting to be abandoned by tourists. With technology, tourists become more aware of tourism destinations, products offered and compare prices resulting in more experienced and sophisticated tourists, tourists are no longer willing to compromise with mediocre services. This is supported by the findings of Porter (1985), Kandampully (1997), Yeoh and Roth (1999), Kotler and Susanto (2001), Kotler (2002), and Tjiptono and Chandra (2011). Positive word of mouth promotion with positive recommendations from trusted people (experts, friends, family, and media publications) is more quickly accepted as references, because tourists have difficulty evaluating tourism products or services that he has not felt himself, considering that the dominant tourist is the first time visitor. Positive word of mouth can be created if tourism products exceed tourist expectations.

\section{CONCLUSION AND SUGGESTIONS}

Based on the results and discussion, it can be concluded that the satisfaction index for the quality of the tourist experience shows an average value of 84.17 (very satisfied). When 
viewed from each indicator, Bali tourism destinations are superior in indicators of hedonism, refresh, involvement and recognition compared to tourist attraction used as the sample in this study. However, the quality of the tourist experience on indicators of novelty, local culture, knowledge, peace of mind, environment, service providers, satisfaction, giving recommendations, and the quality of the destination felt can refer to the tourist attractions of Penglipuran Village as a model for quality tourism development seen from the variable quality of experience. traveler. Meanwhile, the quality of tourist experience in the meaningful indicator can refer to the tourist attraction of Tirta Empul as a quality tourism model seen from the variable quality of tourist experience. The quality of the tourist experience on tourist attractions and tourism destinations in Bali needs to be continuously improved, especially in indicators of hedonism, novelty, meaning, recognition and perceived quality of the destination. The suggestion of this study are: 1) Quality tourism requires the application of quality management at every line of the organization with high idealism and commitment and the continuity of efforts of all stakeholders to carry out management and operational quality tourism standards; 2) The need to develop an organizational quality culture, formulation of standards and guidelines, and quality criteria which are benchmarks for international standards; and 3) The importance of measuring the quality of tourism products with a certification label to ensure the position and things that need to be improved regarding the quality of tourist experience from time to time.

\section{REFERENCES}

1. Aliman, Nor Khasimah, Shareena Mohamed Hashim, and Siti Daleela Mohd Wahid. 2016. Tourists' Satisfaction with a Destination: An Investigation on Visitors to Langkawi Island. International Journal of Marketing Studies 8 (3): 173, DOI: 10.5539/ijms.v8n3p173.

2. Anjos, Sara Joana Gadotti dos, Jessica Vieira de Souza Meira, Melise de Lima Pereira, and Pablo Flores Limberger. 2017. Quality Attributes of Jericoacoara, Brazil. International Journal of Tourism Cities, 3 (2): 196-204.

3. Badan Pusat Statistik (BPS) Provinsi Bali. 2018. Provinsi Bali dalam Angka Bali. Bali: CV. Bhineka Karya.

4. Barsky, J. 1995. World-Class Customer Satisfaction. London: Irwin.

5. Berry, L. 1995. On Great Service: A Framework for Action. New York: Free Press.

6. Baker, Dwayne A. and John L. Crompton. 2000. Quality, Satisfaction and Behavioral Intentions. Annals of Tourism Research, 27 (3): 785-804. DOI: 10.1016/S01607383(99)00108-5.

7. Blazeska, Daliborka, Zoran Strezovski, and Angela Milenkovska Klimoska. 2018. The Influence of Tourist Infrastructure on the Tourist Satisfaction in Ohrid. UTMS Journal of Economics, 9 (1): 85-93.

8. Bowen David and Jackie Clarke. 2009. Contemporary Tourist Behavior. London: CABI Publishing.

9. Chang, Ting-Yueh and Shun-Ching Horng. 2010. Conceptualizing and Measuring Experience Quality: The Customer's Perspective. The Service Industries Journal 30 (14): 2.401-2.419.

10. Chen, Ching-Fu and Dung Chun Tsai. 2007. How Destination Image and Evaluative Factors Affect Behavioral Intentions? Tourism Management, 28 (4): 1.115-1.122. DOI: 10.1016/j.tourman.2006.07.007.

11. Chi, Christina Geng-Qing and Hailin Qu. 2007. Examining the Structural Relationships of Destination Image, Tourist Satisfaction and Destination Loyalty: An Integrated Approach. Tourism Management 29 (4): 624-636. DOI: 10.1016/j.tourman.2007.06.007.

12. Chong, Ka Leong. 2019. The Side Effects of Mass Tourism: The Voices of Bali Islanders. Asia Pacific Journal of Tourism Research 25 (2020-Issue 2): 157-169. DOI: 10.1080/10941665.2019.1683591.

13. Creswell, John W. 2014. Research Design Qualitative Quantitative and Mixed Methods Approaches ( $4^{\text {th }}$ ed.). United State of America: Sage Publications Inc. 
14. Dalimunthe, Gallang Perdhana, Yuyus Suryana, Dwi Kartini, Diana Sari. 2019. A Literature Review of Experience Quality, Destination Image, Perceived Value, Customer Engagement, and Behavior Intention of Bali's Subak Visitors. Global Business and Management Research: An International Journal, 11 (1) 2019, Special Issues.

15. Dioko, Leonardo (Don) A.N. and Amy S.I. So. 2017. Residents' Quality Of Life and Visitors' Quality of Experience Revisiting Tourism Carrying Capacity in Macao. Worldwide Hospitality and Tourism Themes, 9 (3): 349-360. Emerald Publishing Limited 1755-4217. DOI 10.1108/WHATT-02-2017-0006.

16. Dinas Pariwisata Provinsi Bali. 2018. Bali Tourism Statistic 2018 (Statistik Pariwisata Bali 2018). Denpasar: Bali Government Tourism Office.

17. Frenandes, Teresa and Mariana Cruz. 2016. Dimensions and Outcomes of Experiences Quality in Tourism: The Case of Port Wine Cellars. Journal of Retailing and Consumer Service, 31: 371-379.

18. Filieri, Raffaele, Frase McLeay, and Bruce Tsui. 2017. Antecedents of Travelers' Satisfaction and Purchase Intention from Social Commerce Websites. In Schegg, R. and Stangl, B. (Eds.). Information and Communication Technologies in Tourism 2017, Proceedings of the International Conference in Rome, Italy, January 24-26, 2017. Springer, Wien, pp. 517-528. http://www.springer.com/gp/book/9783319511672. DOI: 10.1007/978-3-319-51168-9_37.

19. Gherco, Alina Valentina and Adina Trandafir. 2014. Tourism Development in the Terms of Sustainable Development in Romania. Economics, Management, and Financial Markets, 9 (1): 207-212. ISSN 1842-3191.

20. Giese, Joan L. and Joseph A. Cote. 2002. Defining Consumer Satisfaction. Academy of Marketing Science Review, $2.000 \quad$ (1). Available: http://www.amsreview.org/articles/giese01-2000.pdf Copyright (c) 2002 - Academy of Marketing Science.

21. Gronroos, C. 2007. Service Management and Marketing: Customer Management in Service Competition. 3rd rev. Ed. New York: John Wiley \& Sons.

22. Ismail, Mohd Noor Ismawi, Mohd Hanafiah, Norliza Aminuddin, and Norazah Mustafa. 2016. Community-Based Homestay Service Quality, Visitor Satisfaction, and Behavioral Intention. Procedia-Social and Behavior Sciences 222: 398-405.

23. Kim, Aise Kyoungjin and Graham Brown. 2012. Understanding the Relationships between Perceived Travel Experiences, Overall Satisfaction, and Destination Loyalty. Anatolia - An International Journal of Tourism and Hospitality Research, 23 (3): 328-347. DOI: 10.1080/13032917.2012.696272.

24. Kim, Jong-Hyeong, JR. Brend Ritchie, and Bryan McCormick. 2012. Development of a scale to Measure Memorable Tourism Experiences. Journal of Travel Research, 51 (1): 12-25. DOI: $10.1177 / 004728751038546$.

25. Kotler, Philip, dan A. B. Susanto. 2001. Manajemen Pemasaran di Indonesia, Analisis, Perencanaan, Implementasi dan Pengendalian. Jakarta: Salemba Empat.

26. Kotler, Philip. 2002. Marketing Management. Edinburgh: Prentice Hall.

27. Kozak, Metin and Mike Rimmington. 2000. Tourist Satisfaction with Mallorca, Spain, as an Off-Season Holiday Destination. Journal of Travel Research, 38 (3): 260-269. DOI: $10.1177 / 004728750003800308$.

28. Ladhari, Riadh. 2009. Service Quality, Emotional Satisfaction, and Behavioral Intentions: A Study in the Hotel Industry. Managing Service Quality, 19 (3): 308-331.

29. Larsen, Svein. 2007. Aspects of a Psychology of the Tourist Experience. Scandinavian Journal of Hospitality and Tourism, 7 (1): 7-18. DOI: 10.1080/15022250701226014.

30. Pender, Lesley and Richard Sharpley. 2005. The Management of Tourism. London: SAGE Publication.

31. Porter, Michael E. 1985. Competitive Advantage, Creating and Sustaining Superior Performance. New York: United States of America.

32. Qu, Hailin, Lisa Hyunjung, and Holly Hyanjung Im. 2011. A Model of Destination Branding: Integrating the Concepts of the Branding and Destination Image. Tourism Management, 32 (3): 465-476. DOI: 10.1016/j.tourman.2010.03.014. 
33. Radder, Laetitia and Xiliang Han. 2013. Perceived Quality, Visitor Satisfaction and Cinative Loyalty in South African Heritage Museums. International Business \& Economics Research Journal, 12 (10), October 2013.

34. Rajaratnam, Sushila Devi, Vikneswaran Nair, Saeed Pahlevan Sharif, Uma Thevi Munikrishnan. 2015. Destination Quality and Tourists' Behavioral Intentions: Rural Tourist Destinations in Malaysia. Worldwide Hospitality and Tourism Themes, 7 (5): 463-472 (c) Emerald Group Publishing Limited 1755-4217 DOI 10.1108/WHATT-06-2015-0026.

35. Ryan, Chris. 2002. From Motivation to Assessment. In Chris Ryan (Eds.). The Tourist Experience: 58-77. London: Continuum.

36. Saha, Gour C. and Theingi. 2009. Service Quality, Satisfaction, and Behavioral Intentions: A Study of Lowcost Airline Carriers in Thailand. Managing Service Quality, 19 (3): 350-372. DOI: 10.1108/09604520910955348.

37. Schlesinger, Walesska, Amparo Cervera and Carmen Perez-Cabanero. 2015. Contrasting Quality of Service Experience for Northern and Southern Mediterranean Tourists. Journal of Business, 10 (3): 327-337. DOI 10.1108/EMJB-09-2014-0032.

38. Schnaars, Steven P. 1991. Marketing Strategy: a Customer Driven Approach. New York: The Free Press.

39. Selstad, Leif. 2007. The Social Anthropology of the Tourist Experience. Exploring the "Middle Role". Scandinavian Journal of Hospitality and Tourism, 7 (1), 19-33. DOI: 10.1080/15022250701256771.

40. Smith, Mary-Anne, Gayle Jennings, and Anoop Patiar. 2016. Quality Tourism Experiences: A Qualitative Study of Australian Gold Coast Residents' Perspectives as in a Group Tour to China. Travel and Tourism Research Association: Advancing Tourism Research Globally. https://scholarworks.umass.edu/ttra/2014/Student_Colloquium/9.

41. Soteriades, Marios. 2017. Experiential Dimensions and Their Influence on Behavioral Intentions within the Context of Nature-Based Tourism. Tourism and Hospitality Management, 23 (1): 35-50. DOI: 10.20867/thm.23.1.7.

42. Stamboulis, Yeoryios and Pantoleon Skayannis. 2003. Innovation Strategies and Technology for Experience-Based Tourism. Tourism Management, 24 (1): 35-43. DOI: 10.1016/S0261-5177(02)00047-X.

43. Sukanthasirikul, Kanchana and Wannee Trongpanich. 2015. Cultural Tourism Experience on Customer Satisfaction: Evidence from Thailand. $10^{\text {th }}$ International Scientific Conference on Economic and Social Development-Miami, $25^{\text {th }}$ September 2015.

44. Tjiptono, Fandy dan Gregorius Chandra. 2011. Pemasaran Strategik. Edisi 2. Yogyakarta: Penerbit ANDI.

45. Wang, Tz-Li, Phuong Thi Kim Tran, and Vinh Trung Tran. 2017. Destination Perceived Quality, Tourist Satisfaction and Word-of-Mouth. Tourism Review, 72 (4): 392-410. Emerald Publishing Limited. ISSN 1660-5373. DOI 10.1108/TR-06-2017-0103.

46. Yeoh, Poh-Lin and Kendall Roth. 1999. An Empirical Analysis of Sustained Advantage in the U.S. Pharmaceutical industry: Impact of Firm Resources and Capabilities. Strategy Management Industry, 20: 637-653. DOI: 10.1002/(SICl)10970266(199907)20:7<637::AID-SMJ42>3.0.CO;2-Z.

47. Yu, Xin and Betty Weiler. 2001. Mainland Chinese Pleasure Travelers to Australia: a Leisure Behavior Analysis. Tourism Culture and Communication, 3 (2): 81-91.

48. Yuksel, Atila, Fisun Yuksel, and Yasin Bilim. 2010. Destination Attachment: Effects on Customer Satisfaction and Cognitive, Affective and Conative Loyalty. Tourism Management, 31 (2): 274-284. DOI: 10.1016/j.tourman.2009.03.007.

49. Zeithaml Valarie A., Leonard L. Berry and A. Parasuraman. 1993. The Nature and Determinants of Customer Expectations of Service. Journal of the Academy of Marketing Science, 21 (1): 1-12. DOI: 10.1177/0092070393211001. 